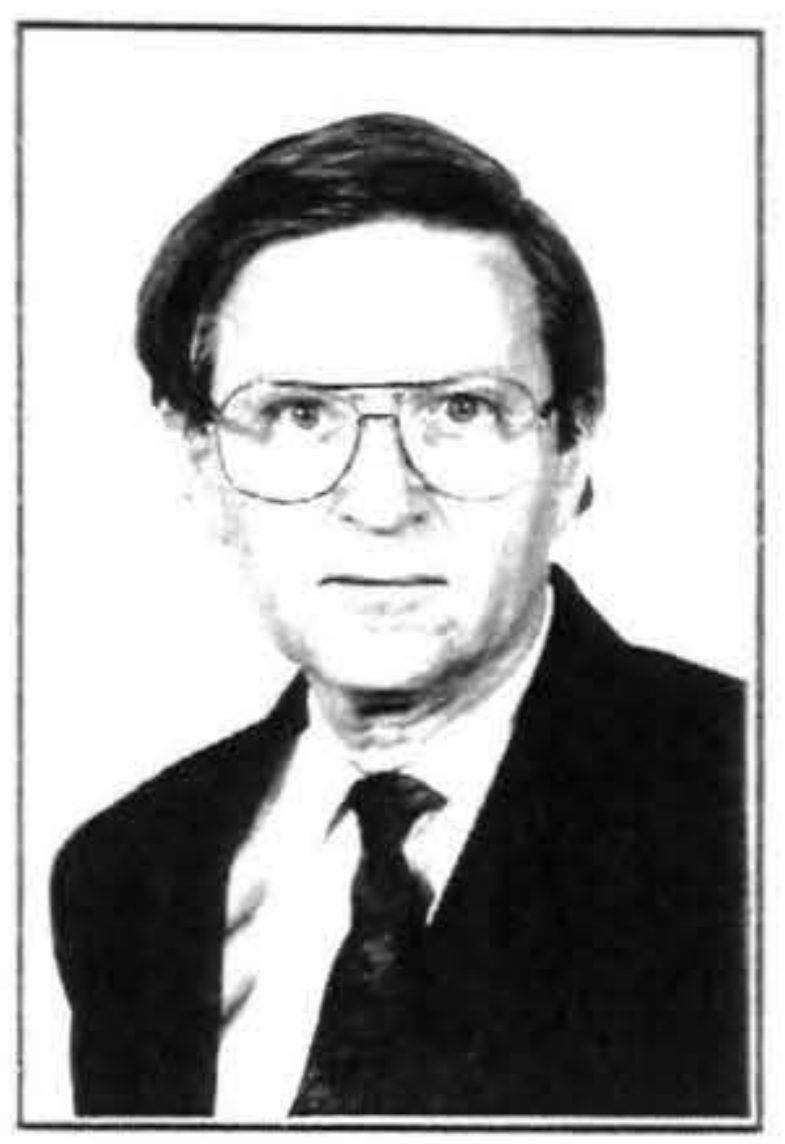

\title{
THE RATIONING MODEL AND REGIONAL LABOUR MARKETS
}

\author{
L. Fraser Jackson \\ Victoria University of Wellington
}

\begin{abstract}
This paper examines data on regional labour markets, and discusses a means of comparing the development of those markets over the period between 1986 and 1991. A simple model is considered for future estimation using data on electorates. Major differences in patterns of employment and remuneration in different parts of the country are found and factors associated with these are explored. These differences are examined against the background of some of the leading arguments for the Employment Contracts Act, and it is shown that local factors have been a dominant factor in setting remuneration over the period studied.
\end{abstract}

George Box(1994) has characterised the development of scientific knowledge as the application of an iterative loop involving, a model, deductions from the model, observation of data, and induction which leads to revision or refinement of the model. In examining the labour market in New Zealand, two broad approaches have been used to model the market. Examples of those based on time series are studies by Grimes(1981), Brooks(1991) and Rae(1994). These models have generally attempted to model labour supply, labour demand, and wage change, with a careful treatment of the dynamics of the relationships between these aggregates. Examples of the alternative crosssection based studies are those of Neild(1971), Hyman(1979), Raney(1990), Harris and Raney(1991) and Harris(1993). In contrast to the time series studies, these have concentrated on the labour force participation decision (the supply function) and apart from the work of Neild have not attempted to construct a market model.

Our long term objective is to construct a model which like Neild, attempts to look at the whole market. On the supply side it should distinguish both gender and the fulltime/ part-time decision, since there have been very important changes in the ratio of participants in these categories. The demand side clearly present more problems, since disaggregated data for regional employers is not readily available, but it may be possible to model some aspects of the fulltime/part-time split from the employers perspective. Finally the model should include some wage adjustment dynamics. This paper should be considered as examining some of the data to assess parts of altemative model structures.

The most important change in the theory since the work of Neild is the exploration of disequilibrium macro-economics. Barro and Grossman $(1971,1976)$, Dreze(1975) and
Benassy(1975) all contributed to this, and Malinvaud(1977) provided a simple model which made these ideas more widely accessible. In characterising alternative situations with a buyers market for labour, Malinvaud distinguished what he called Keynesian unemployment and classical unemployment. In Keynesian unemployment, firms are prepared to supply more at current prices (i.e. are rationed with respect to their demand) and this is reflected in the labour market with households only able to sell their labour up to the level demanded by firms, even though they are prepared to provide more at current wage rates (i.e they are rationed with respect to labour supplied).

Sneesens(1984) and Artus, Laroque and Michel(1984) provided empirical models using these disequilibrium ideas, and Lambert(1998) provided the first detailed integration of micro-disequilibria into them. None of the previous cross-section models of the New Zealand labour market have given serious attention to disequilibrium behaviour in the labour market. In the spirit of Box's characterisation, this paper will show that dominant features of the data on changes between 1986 and 1991 are consistent with some implications of rationing models. These are models in which employment at the individual level is not determined solely by market variables.

\section{Implications of the rationing model}

The period from 1984 to 1991 was a period of exceptional change in the New Zealand economy. Major price and legal changes occurred, and under the pressures these provided, many firms made major changes in productivity. Firms were left exposed to market conditions, and thus forced to bear a larger share of the risk associated with any market changes themselves. 
In the absence of price and productivity changes, a rationing model would imply that the demand for variable factors of production would vary directly with the level of output with nochange in the terms on which the factors are purchased. We would therefore expect the numbers of fulltime employees of both sexes drawn from cross section units to vary in a proportionate way. We would alsoexpect the numbers of part-time employees of both sexes to vary similarly.

In a period of rapid change, part-time employees provide more flexibility. Some of the change in the numbers of fulltime employees may be merely substitution of parttime for fulltime employees. Whether from changes in uncertainty associated with demand, or from changes in input prices, this substitution effect would be expected to affect nearly all regions. We will show that there is evidence that the substitution effect was experiencedacross the country in a relatively uniform way, and there was much more cross sectional variability associated with the changes in the numbers in employment.

Changes in the relative prices of inputs will complicate these changes. If there is pressure on profits we would expect substitution away from the relatively higher priced inputs. This would lead to increases in the numbers of females employed if they are available and under a pure rationing scenario, they could be obtained at the same relative price. Over the period of our study there was an increase in the relative incomes of women. In view of the fact that there were considerable numbers of unemployed, we need to look at factors other than the supply curve for reasons for these increases. They may have been driven largely by equity or faimess considerations between those employed. For whatever reason these increases would reduce the incentive for substitution. However the income differentials between male and female employees in the same occupational groups suggest that there is still considerable scope for further changes in relative prices and input ratios.

To construct a sharp test of the rationing model it is necessary to have good wage data as well as numbers employed. In the rationing model, the labour supply is horizontal at the going wage, up to the the level determined by the labour supply function, so a prediction would be that there is substantial change in numbers employed without changes in the wage. In the data section we will outline why further work is necessary before this aspect of the model can be tested.

\section{The units of analysis and data}

This paper uses a cross section approach to labour markets because it provides an opportunity to examine behaviour under different conditions at the same point in time. Across regions there is varying industry and occupation structure modifying the demand for labour. There is also variety in age structure, other demographic variables and incomes providng changes in labour supply.

We chose to use electorates determined for the 1987 election as the units of analysis. Advantages of electorates are that they are of similar size, often display some "community of interest' and they reflect the regional diversity of the country. Against these we must note that they are not independent markets. Adjacent electorates will often be affected by similar labour market factors, but adjacency can be described. They also reflect other social factors which influence individual residential decisions, but this does not detract from their ability to portray the interactions of individuals with the labour market. Indeed aggregates of like individuals are generally considered advantageous in attempts to use aggregated data for behavioural studies. As aggregates they still suffer from all of the difficulties of aggregation, and its ability to confound and bias effects.

Migration between the fixed areas also increases the difficulties of identifying dynamics in the market. Migration is influenced by labour market differences, and itself modifies the labour market.

Within each electorate the labour force status categories, fulltime, part-time, unemployed and non-labour-force are distinguished for both sexes. The Statistics New Zealand database SUPERMAP 2 provides a table giving the number of persons in each electorate by labour force status, sex and income from the 1991 census. Statistics New Zealand prepared a table of the same structure for the 1986 census. Many other characteristics are also available for these units, but we will use few of them in this paper. From these tables it is possible to estimate mean incomes for each labour force status group, if an assumption is made about the mean for the open ended class. The Pareto distribution models the upper tail of the income distribution in New Zealand reasonably well and for the range of tail parameters observed, using 1.667 times the class lower bound provides a plausible approximation to the mean for the open ended class.

\section{Changes in incomes}

In labour market analyses it is usual to look at wages and units of labour expressed in hours. With census data, the only observable is the income generated from wages or salaries plus other income to give total income. Constant incomes need not mean constant wage or salary rates. We can however observe income distributions for four labour market categories. Clearly those currently unemployed or not in the labour force often have other income, or have had periods of employment within the income year reported in the census. Separating these groups reduces the potentially large effects on average income of the changes in the proportions in each group.

Table 1 illustrates the ratio of incomes in 1991 to 1986. The range of 37 to 80 percent in increases in mean incomes of males who are fulltime members of the labour force emphasizes the diversity of the experience in different 
areas. Over the period the Consumers Price Index increased by 50 percent, so there were many areas where real incomes declined. It is noteworthy that for all groups of females the mean real incomes rose.

\section{Table 1. Ratio of electorate mean income in 1991 to mean income in 1986. Extreme values}

\begin{tabular}{lllllllll}
\hline \multicolumn{2}{l|}{ Males } & \multicolumn{4}{|c}{ Females } \\
\hline \multicolumn{3}{c|}{ MFT MPT MUE MNLF } & FFT & FPT & FUE FNLF \\
\hline Max & 1.80 & 1.65 & 2.54 & 1.56 & 1.84 & 1.85 & 2.73 & 1.78 \\
Min & 1.37 & 0.96 & 1.14 & 1.25 & 1.54 & 1.49 & 1.55 & 1.43 \\
Mean & 1.55 & 1.30 & 1.68 & 1.38 & 1.64 & 1.65 & 1.96 & 1.60 \\
\hline
\end{tabular}

Note: Table value is ratio of mean income in 1991 to mean income in 1986.

Source: Statistics New Zealand, SUPERMAP2.

Over a five year period we might anticipate that changes in relative prices, especially of commodities, would generate substantial changes in earnings for industry groups. Given regional differences in goods produced this will generate changes in regional relative incomes. Without comparative data for other periods it is not possible to assert whether the level of change in relative earnings in Table 1 is to be expected, but changes of 30 percent in relative mean earnings must have important social and economic implications.

There was also change in the employment levels in the electorates. The income generated in each electorate is the product of the relative mean earnings and numbers employed. For males, the lowest growth in income generated in an electorate was 13 percent, and the highest was 91 percent. For females the ratios were higher, with the lowest growth 49 percent and the highest 118 percent. The differential pattern for males and females means that the total range of growth rates is not so extreme, but still large, with a minimum of 28 percent growth and a maximum of 100 percent growth. If the electorates are sorted in order of increasing total income growth it is not surprising to find electorates like Albany, Kapiti, Kaimai and West Auckland are at the end of this list. All experienced substantial population growth during the period. They imply that an adequate model for this data will need to deal with migration.

\section{Occupational change}

Between 1986 and 1991 a new standard classification of occupations was introduced. Even when reduced to a simplified schema with seven categories there were major shifts between these categories between the two censuses. The administrator and manager group had added to it many lower ranked administrative and management tasks, especially from the clerical and technical groupings. Another large group of persons were moved from clerical to technical classifications. These changes undoubtedly influenced the relative mean incomes of the major occupational groups, and table 2 which gives the relative mean income changes between the Censuses at the level of aggregates of published groups provides a very poor guide to what happened. The increases in the first two groups are underestimated because of the addition of numbers of lower paid persons. Those transferred between groups are likely to be among the higher paid in the groups from which they come. If this occupation data related to consistent groups it would permit a different analysis of the nature of income change. Its inadequacy prevents any analysis of those predictions of the rationing model (there will be employment change with no change in the wage rate without major work with the census data.

\section{Changes 1986 to 1991}

In this section of the paper we explore several variable associations, and examine their consistency with alterna-

Table 2. Occupational group by ratio of mean income in 1991 to mean income in 1986

\begin{tabular}{llllllll}
\hline & $\begin{array}{l}\text { Mgmt/ } \\
\text { Admin }\end{array}$ & $\begin{array}{l}\text { Prof/ } \\
\text { Tech }\end{array}$ & $\begin{array}{l}\text { Cler- } \\
\text { ical }\end{array}$ & $\begin{array}{l}\text { Sales/ } \\
\text { Services }\end{array}$ & $\begin{array}{l}\text { Agric } \\
\text { Elem. }\end{array}$ & $\begin{array}{l}\text { Prodn/ } \\
\text { Occup. }\end{array}$ & $\begin{array}{l}\text { Not } \\
\text { Spec }\end{array}$ \\
\hline Males & 1.34 & 1.46 & 1.39 & 1.36 & 1.54 & 1.46 & 1.56 \\
Females & 1.36 & 1.59 & 1.57 & 1.42 & 1.73 & 1.50 & 1.70
\end{tabular}

Numbers by category in 1991

$\begin{array}{lrrrrrrr}\text { Males } & 106585 & 156678 & 32958 & 56079 & 88851 & 283230 & 9939 \\ \text { Females } & 44610 & 113967 & 117402 & 59964 & 26295 & 48549 & 6132\end{array}$

Changes by category from 1986 to 1991

\begin{tabular}{lrrrrrrr} 
Males & 46696 & 46077 & -31686 & -67854 & -20475 & -81351 & 1563 \\
Females & 34236 & 34095 & -33600 & -38361 & -4416 & -14622 & 2733 \\
\hline
\end{tabular}


Figure 1. Changes in the number of fulltime employees in electorates, 1986-1991, females vs males

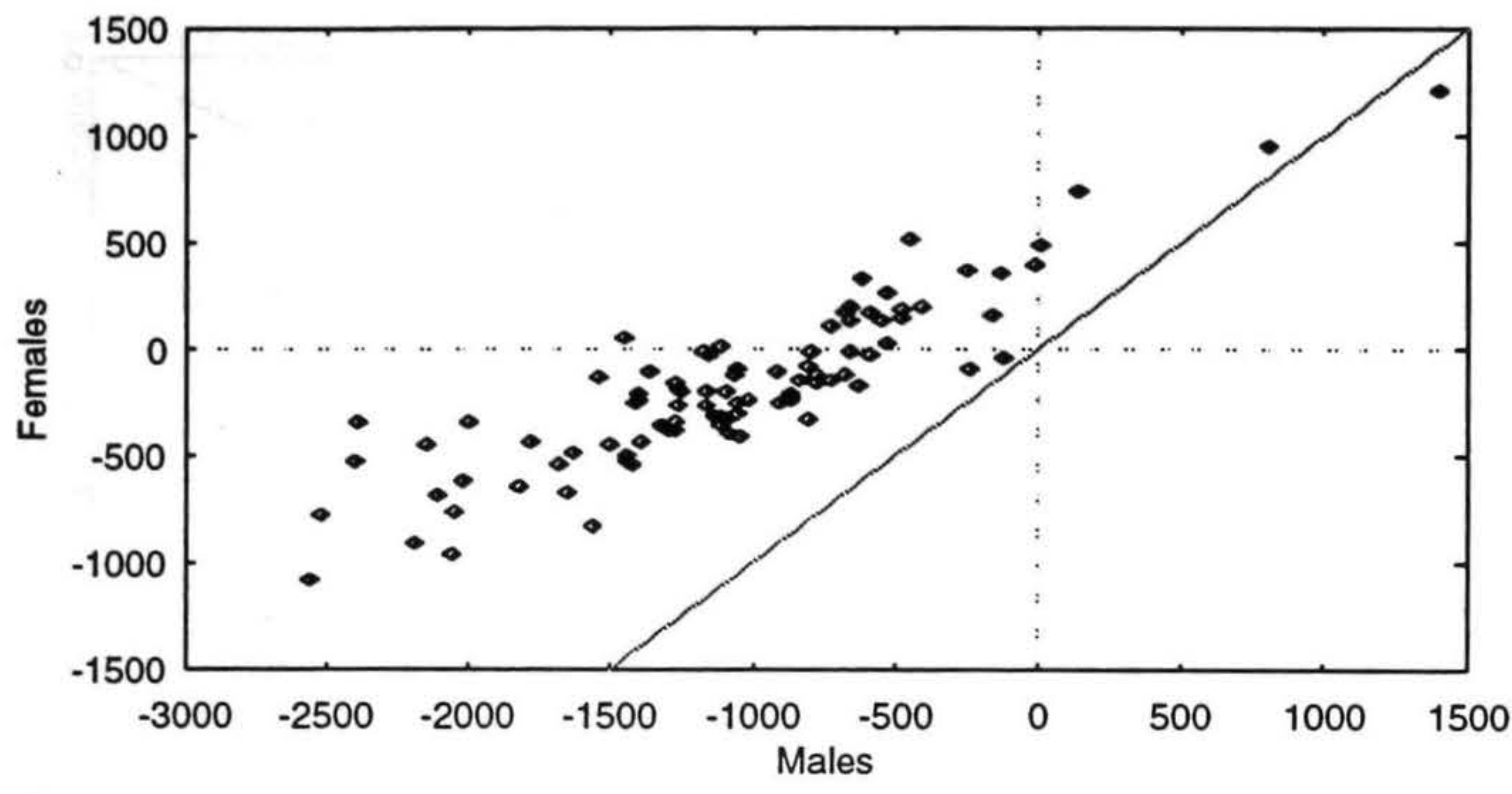

tive ways of modelling the labour market. We will to show that they are consistent with a limited range of major patterns.

The changes in the numbers of fulltime female employees are plotted against changes in male employees, figure 1 . A strong positive association between these changes would be consistent with movements along a supply curve, and the major variation in the data being associated with movements of the demand curve.

There could alternatively be correlated movements both supply and demand in curves which could generate this result, but the correlation between the two sets of changes is high, and tight linking of the changes in the two functions would be required.
Figure 2 illustrates that when we calculate the relative changes in numbers the association is even more striking. It shows that there have not only been strongly associated changes between male and female, but that there has been a clear substitution effect, with the relative change in the numbers of females employed always algebraically larger than the relative change in the numbers of males employed. This substitution effect was very widespread, and remarkably uniform across the country. All electorates experienced a shift towards higher relative female employment, but the direction of greatest variation in the data is in the joint variation in the numbers employed.

Since the males and females within an electorate tend to be employed in related industries, it would be expected that their income changes would be correlated. Figure 3 shows

Figure 2. Changes in the number of fulltime employees in electorates 1986-1991.

Female vs male, ratio scales

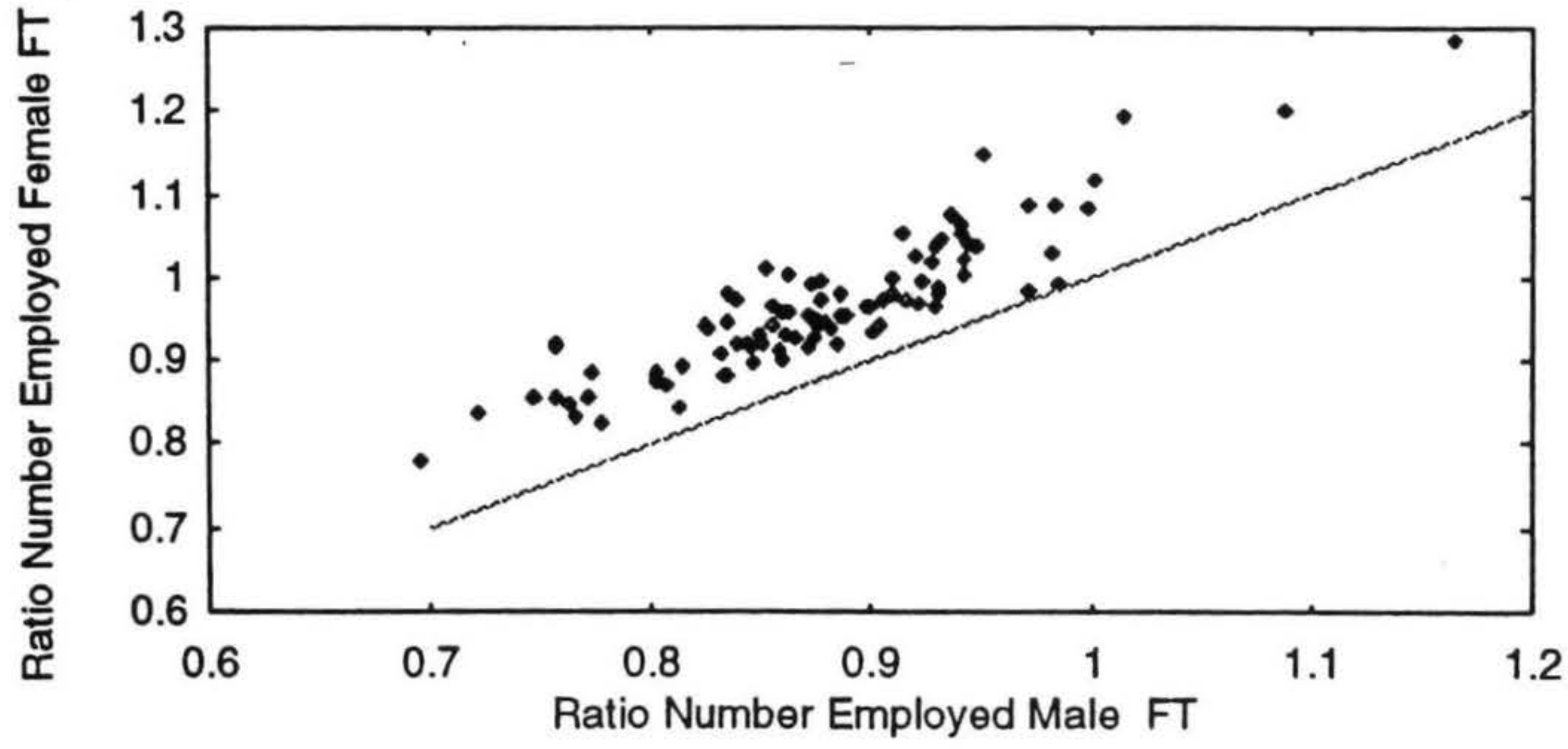


Figure 3. Change in earnings of fulltime employees in electorates, 1986-1991. Female vs male

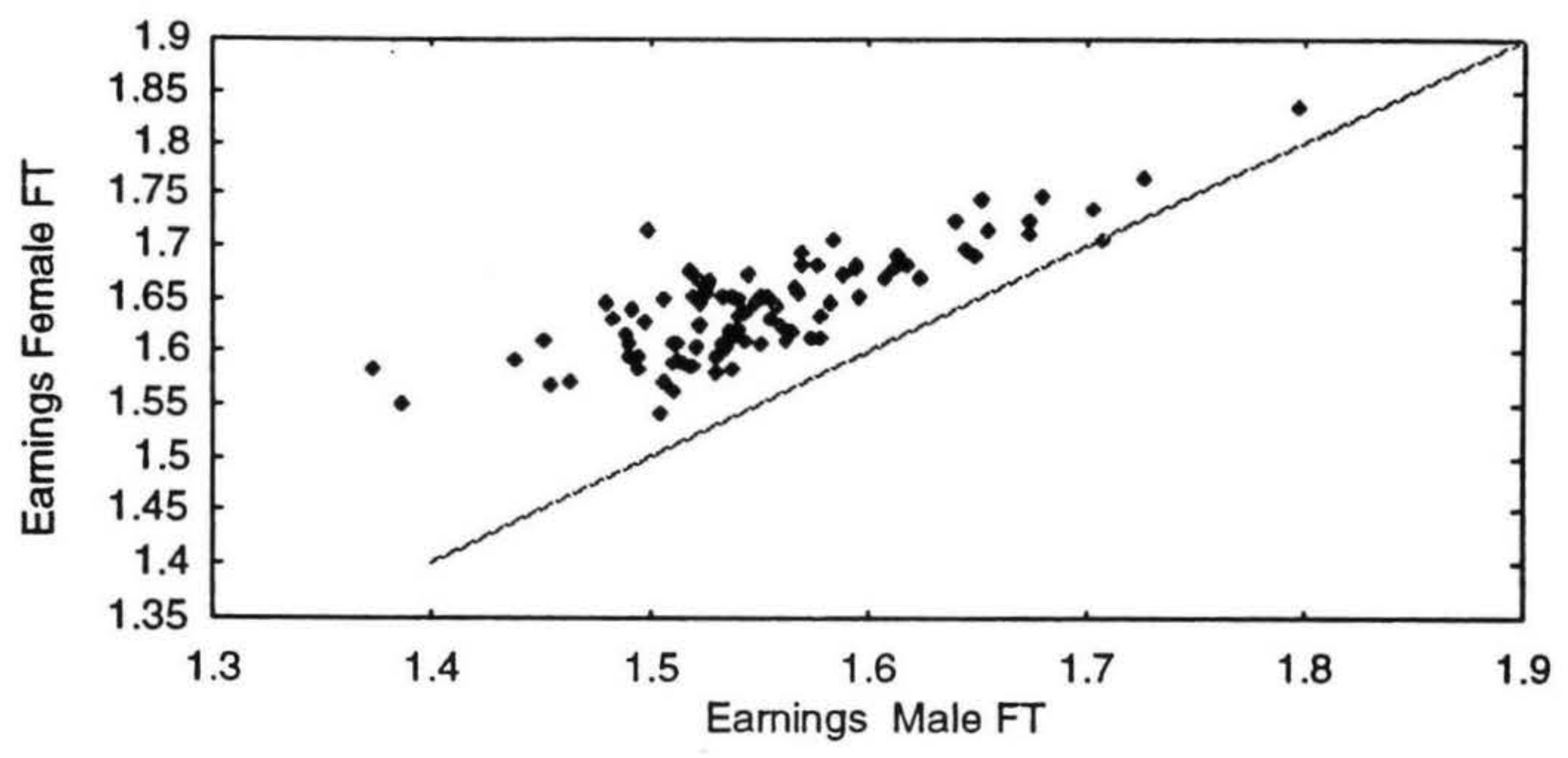

that this is so for fulltime employees.

Further examination of these data would show that there is strong evidence of a decrease in the relative differences of female earnings across electorates, and that female earnings in areas with low rates of increase for males did relatively better. Under the usual equilibrium model, with strong associations in the numbers employed, the pattern in figure 3 would not be inconsistent with variations along a supply curve. A clear test of that can be provided by examining the plot of changes in income vs changes in employment. Figure 4 gives this diagram for males in fulltime employment, and shows a weak positive association. Other evidence suggests that one factor in the positive association is changes in relative numbers and incomes in occupational groups, and that there is left a very weak association between changes in employment and changes in incomes. Thus the evidence for an association between changes in numbers employed and income levels is very weak.

There has been much debate about the shape of the labour supply function and whether or not there are ranges over which it is backward sloping. In this data there appears to be little variation in the prices for substantial variation in the quantities, and the conventional view would interpret that as a highly elastic supply function. An alternative interpretation is the rationing model in which a point on the supply function is only observed when there are no unemployed. In that model, the supply price is fixed by other considerations, and labour is generally available at that price up to the labour supply. In the data in this study, there

Figure 4. Change in income vs change in employment of males employed fulltime in electorates, 1986-1991

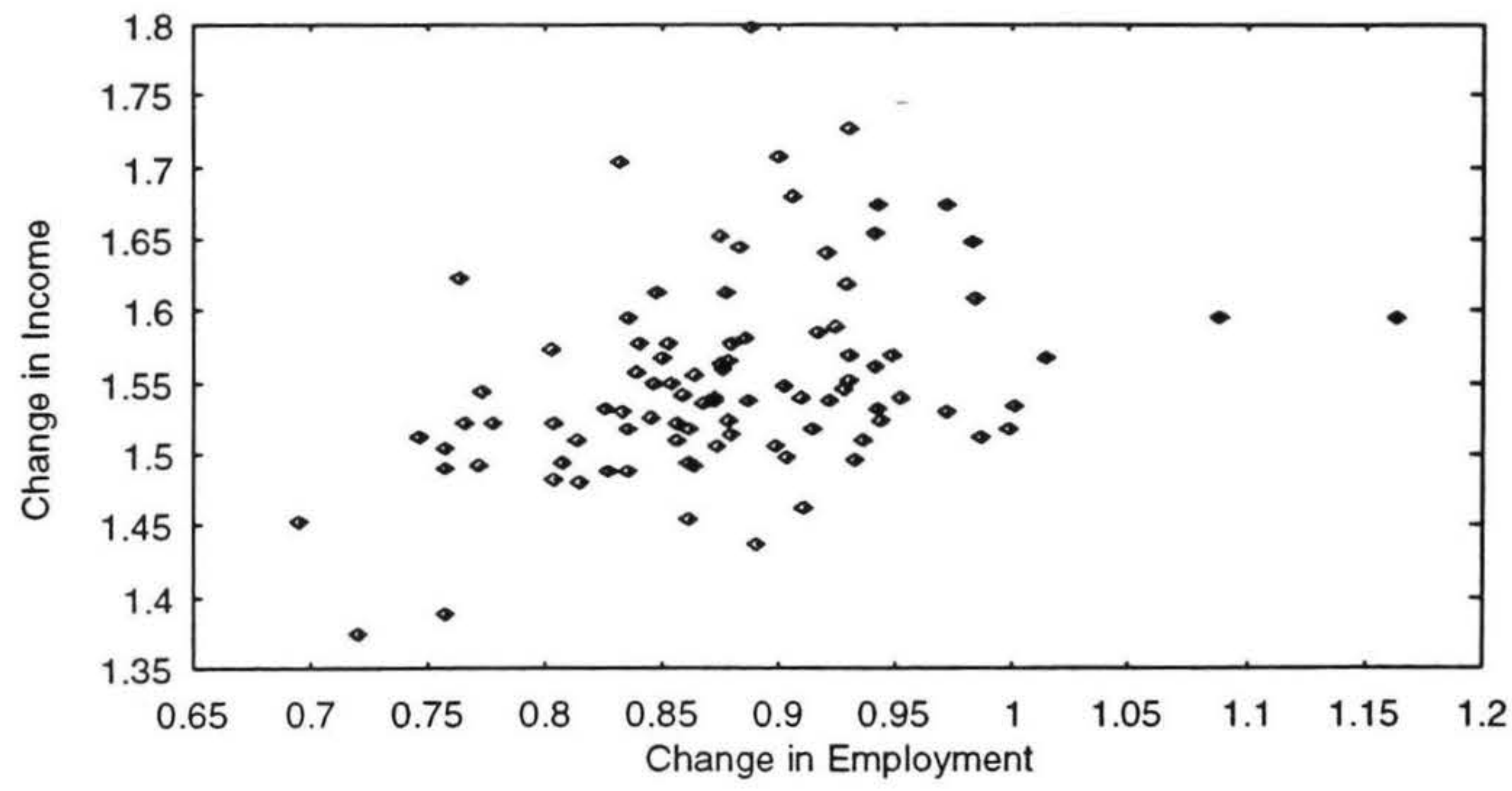


Figure 5. Changes in the number of part-time employees in electorates 1986-1991, female vs male, ratio scales

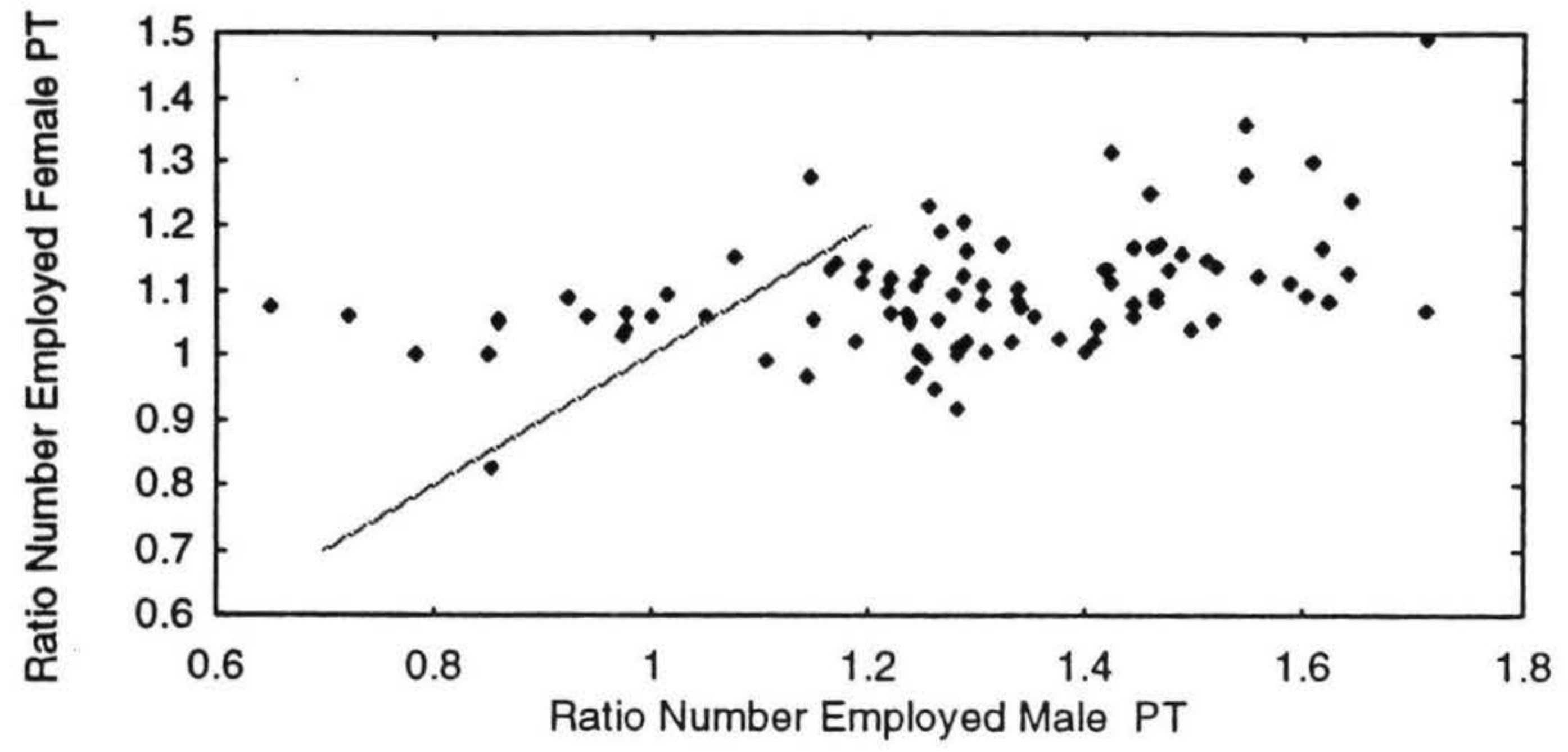

were unemployed in all electorates, so at least in some occupational groups there was excess supply. It would imply that the observed employment levels are on the demand function.

Figure 5 illustrates that for part-time employees there is only a weak to moderate positive association of the changes in the numbers in both sexes, but that in contrast to the changes in fulltime employees there are increases in excess of 80 percent of electorates. However figure 6 illustrates that there was a strong substitution effect, with the pattern of changes in fulltime and part-time employment for females showing the major axis through the points clearly away from the origin. No model has been proposed which would lead to persons having increased preferences for part-time employment over this period.
Given that in all electorates there were persons unemployed, this pattern should probably be interpreted as being determined by employers preferences and consistent with endeavouring to accommodate greater uncertainty and to match labour inputs more precisely with demand. Figure 6 therefore constitutes quite strong evidence in favour of the observed points being on the demand function.

In many contexts those reporting themselves as unemployed and those reporting themselves as not in the labour force are carefully distinguished since there is great public interest in the numbers unemployed. Studies by Silverstone and Gorby (in this volume, 1995) and others have emphasized that some of the largest gross flows are from those 'not in the labour force' into employment, and vice versa.

Figure 6. Change in the number of female part-time vs fulltime employees in electorates, 1986-1991

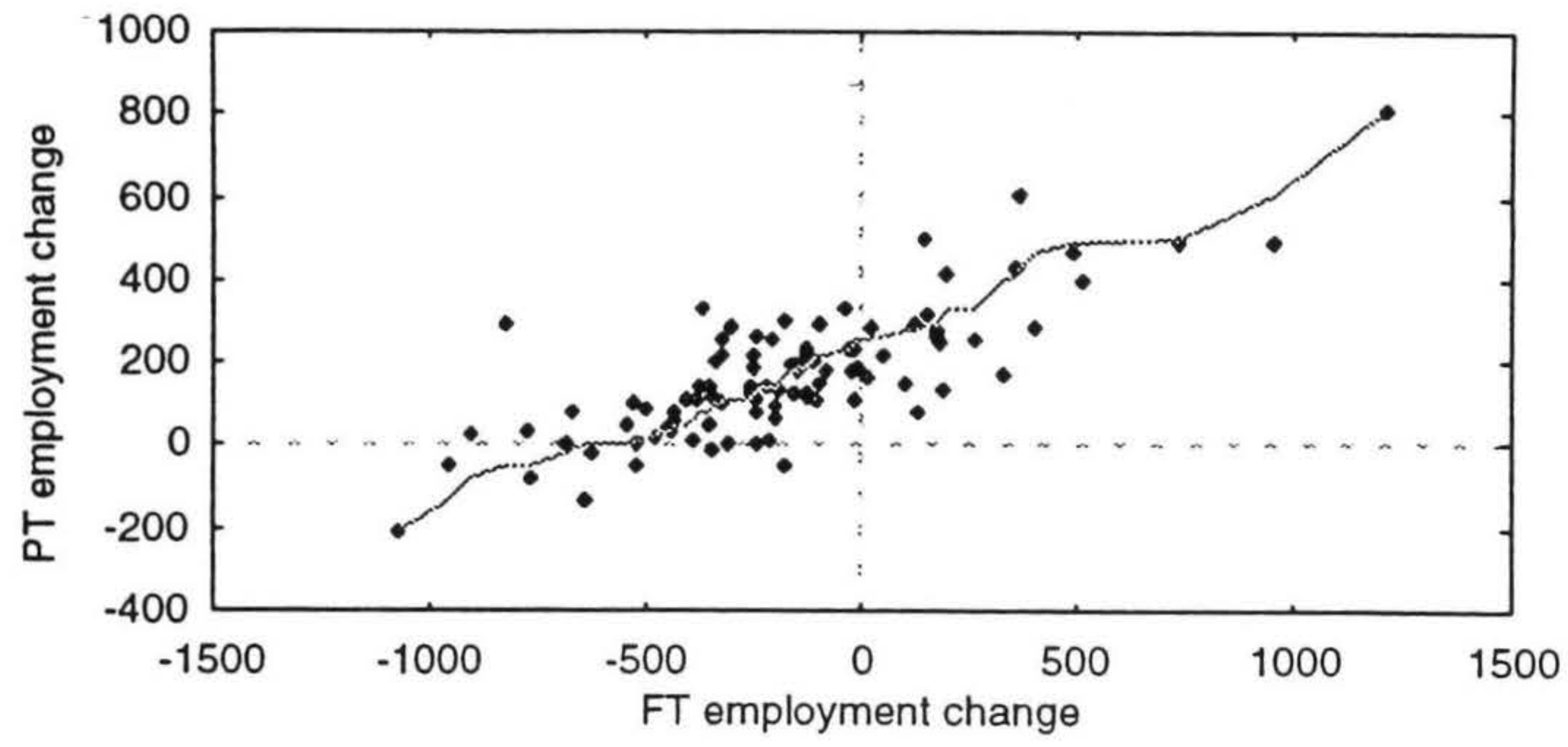


Figure 7. Changes in the number of unemployed females vs unemployed males in electorates, 1986-1991

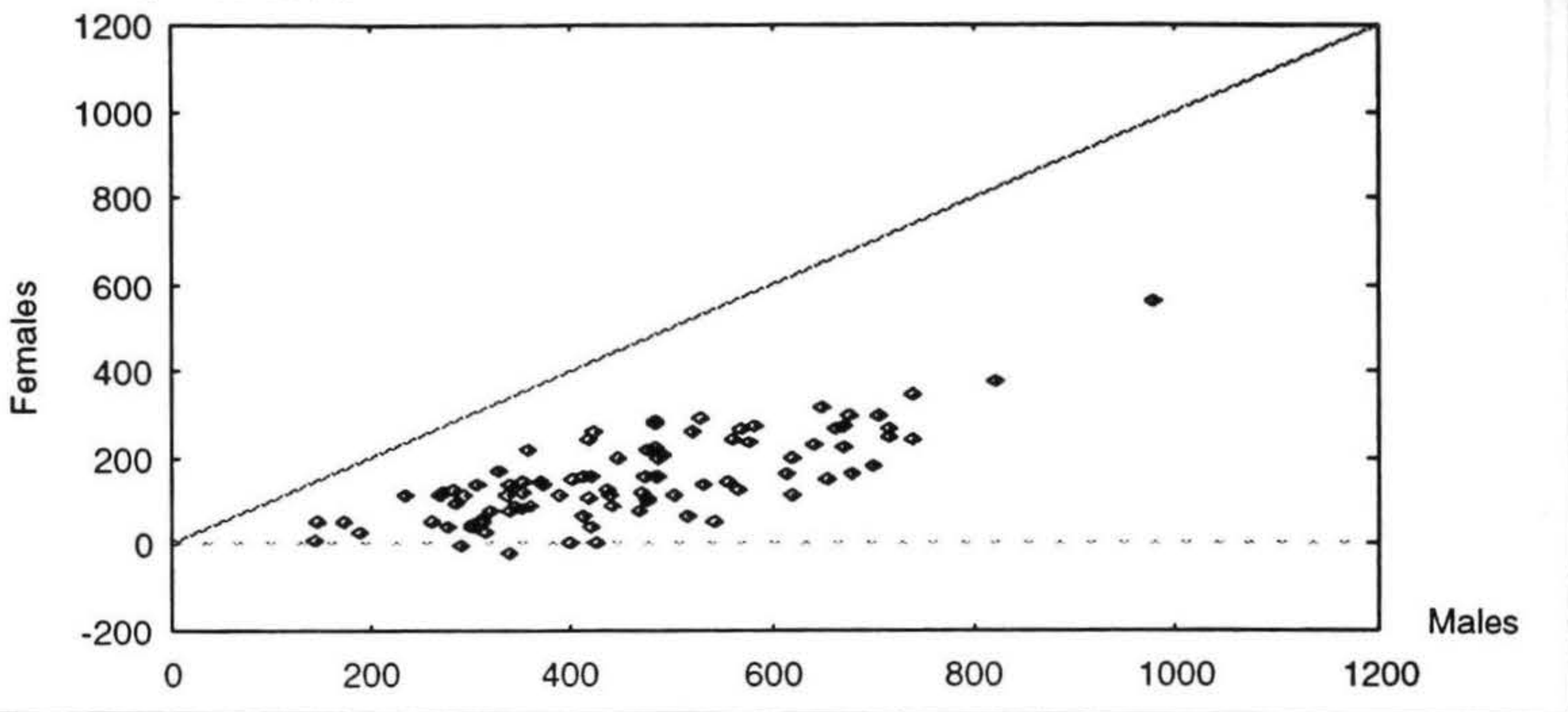

Figure 7 illustrates that changes in numbers of unemployed are much larger for males than females, probably reflecting social responses to lower total employment of persons in households. Figure 8 shows the way in which all but one electorate increase unemployment was associated with simultaneous and layer increase in those reporting themselves not in the labour force. This figure clearly suggests a very strong discouraged worker effect. There is no evidence here of the 'added worker' effect, where additional members of a household enter the labour force when one member becomes unemployed. There may of course be that sort of substitution in an endeavour to maintain household income, and some of that must have happened for the switch between male and female employment which has occurred. However in the aggregates, this data is more consistent with a 'rationing' story. In a rationed market, the probability of getting a job is more associated with chance events such as contacts at the time a job becomes available. Factors which influence the probability of such contacts become important and will give different individuals different probabilities of being in employment at a particular time. The probability of getting a full or part-time position is not so dependent on whether the individual is actively looking for work and that distinction becomes less important to them.

Both of these diagrams suggest that the levels of unemployment in New Zealand reflect, but do not adequately measure the magnitude of the loss of potential income from shortage of demand and under utilisation of the available labour. Employment can clearly increase by very many more than the number of unemployed, and probably in excess of twice their number.

Figure 8. Change in the number of males not in the labour forcevs number of males unemployed in electorates, 1986-1991

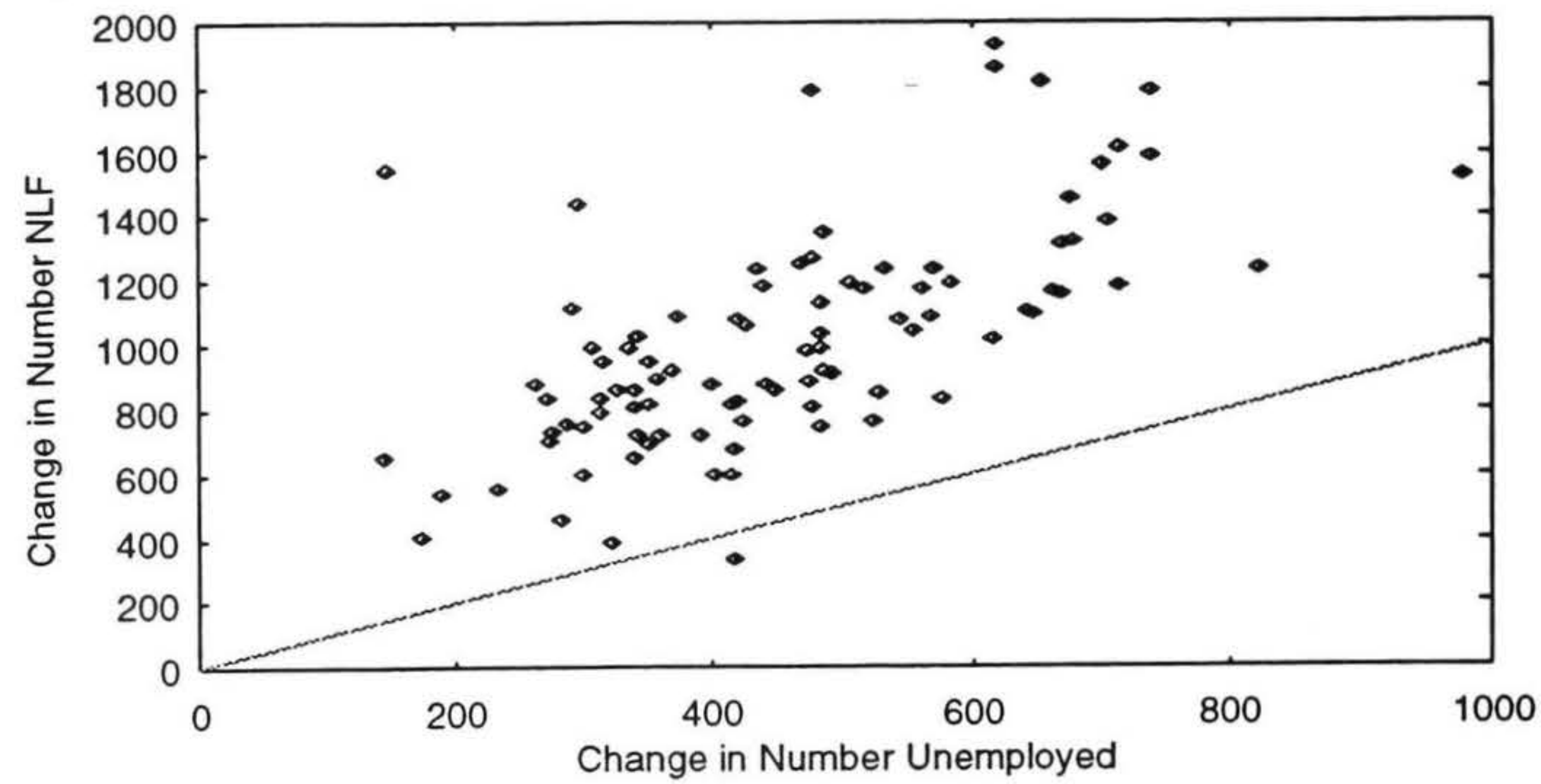




\section{Figure 9. Regression of mean income on occupation-weighted mean income, males employed fulltime in electorates, 1991}

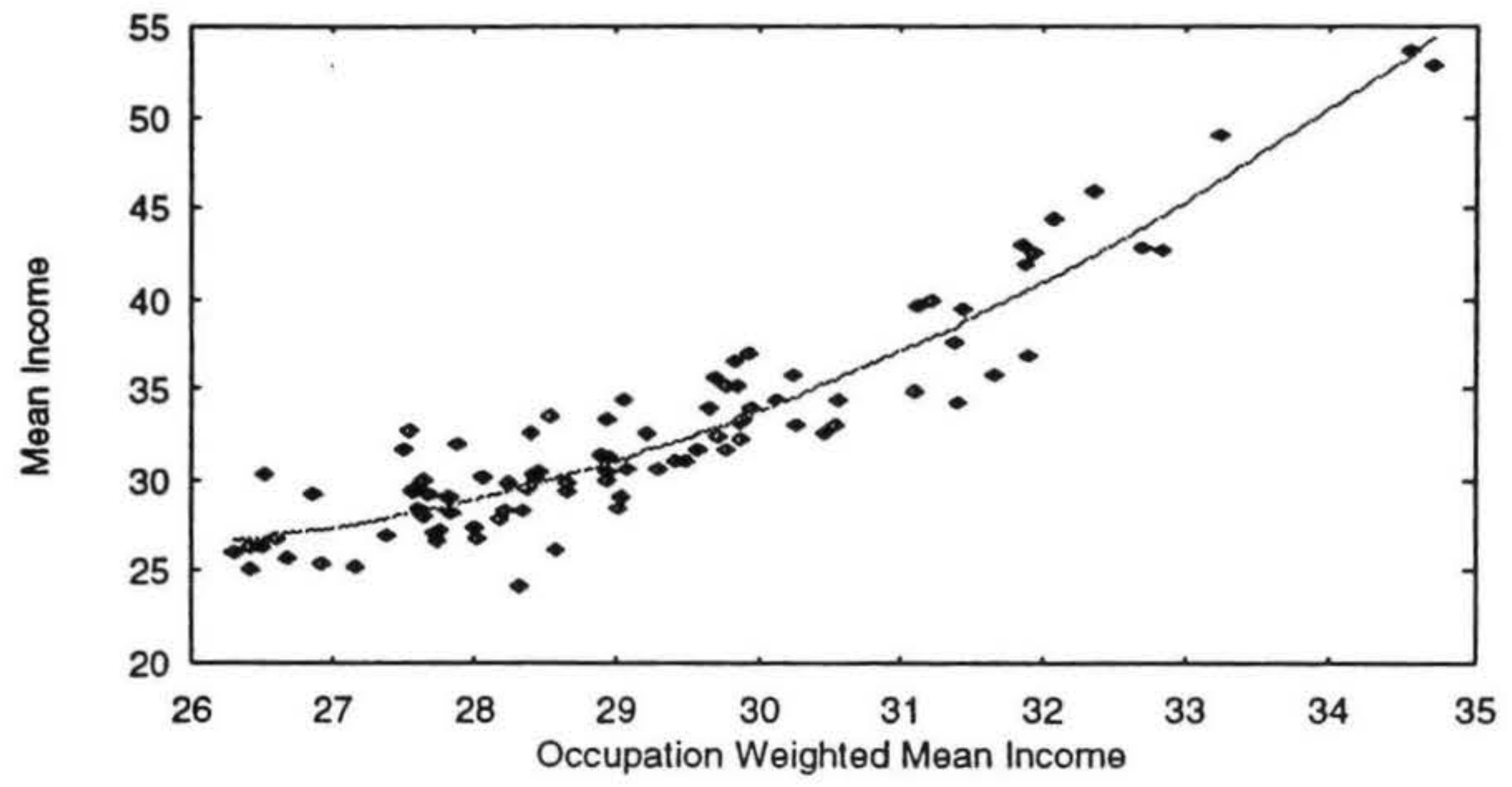

\section{Factors in the income differences between electorates}

So far this paper has focussed on changes between the two census dates. The income differences between electorates are of interest in themselves, and may throw some light on factors important in changing mean incomes for these groups from the population. There are large differences in the proportions in various occupational groups and large income differences between the groups so elimination of these differences are necessary to assess income change.

The national average incomes distinguishing occupational group, but ignoring sex differences, were weighted with the proportions of persons in each occupational group within the electorate to construct an occupation standardised measure of income, INCOW. The plot of this variable against observed mean income for males is given in Figure 9. It clearly demonstrates that the occupation structure is an important determinantof the observed mean income. The relationship is non-linear and increases at a relative marginal rate substantially in excess of one. There are obviously other factors involved in this relation, including the tendency for similar socio-economic groups to locate together irrespective of occupation. It highlights one of the difficulties of using electorates as units. Nevertheless the fact that in excess of 80 percent of the variance in mean incomes of electorates can be considered to be occupation related, emphasizes the importance of institutional factors in the labour market.

Against this background of largely occupation determined income differences it is clearly difficult to assess the effect of other economic factors. Examination of the residuals in the plotted relationship and the similar relationship for females demonstrates that the Auckland and Wellington urban areas appear to depart from the overall pattern, and the South Island generally has lower incomes relative to the national pattern. Thus there appear to be residual economic effects associated with regional labour market conditions.

The major changes in the occupational classification between the two censuses prevent us using existing census data to examine the extent to which changes in occupational earnings, and changes in the distribution of employment between occupations are associated with the changes in incomes between the census dates. Given the magnitude of the occupation effects at the 1991 census date, it is clearly necessary to establish these changes before the relative role of aggregate labour market conditions on incomes can be analysed properly.

In a rationing model, number of persons available for employment at the current wage exceeds the number of jobs available. The probability of getting work may depend on a number of personal or social factors. Some variables which are often included in demand and supply functions, such as educational level, may also be important in the rationing process. The extent of contacts into the labour market mentioned in a number of papers at this conference is another factor and is likely to be linked to other socioeconomic variables. Given the extent to which the same variables may occur in the supply function and also in the rationing process, it may not be possible to identify the supply function, and may only be possible to estimate a reduced form of the model. Research to clarify these issues is essential if we are to truly understand observed unemployment rates especially in subgroups of the population.

\section{Conclusion}

This paper has examined some features of the data, and their consistency with the types of models previously used for studying the labour market. Equilibrium models have dominated past work. It has generally been assumed that the observations will be on the supply function and hence 
determine a participation function. The data on our units do not appear to be consistent with that approach. There are large changes in employment, and the predominant pattern appears to be a quantity adjustment rather than a price adjustment. The observed strong increases in the non-labour force group when unemployment increases provide further evidence that what is observed is something other than changes in the supply function. The increased ratio of female and part-time employees suggest that price and cost factors have influenced the structure of employment but the pattern of quantity variation suggests they play a relatively small role in determining its level.

\section{Future research}

This exercise was begun in an attempt to construct a better cross section model of what is happening in the labour market in New Zealand. It clearly points to the need to have a different framework to models which have been tried in the past. Prior to further progress it is essential to improve the income information, and establish changes in incomes for consistent occupational groups between the two census dates. That in itself would throw a great deal of light on the changes which have taken place.

\section{References}

Artus, P., Laroque, G and G. Michel 1984 Estimation of a quarterly econometric model with quantity rationing. Econometrica 52:1387-414.

Barro, R.J. and H.I. Grossman. 1971 A general disequilibrium model of income and employment. American Economic Review 61: 82-93.

Barro, R.J. and H.I. Grossman. 1976 Money, employment and inflation. Cambridge Universtiy Press. Cambridge.

Benassy, J.-P. 1975 Neo-Keynsian disequilibrium theory in a monetary economy. Review of Economic Studies. 42: 503-523.

Box, G.E.P. 1994 Statistics and quality improvement. Journal of the Royal Statistical Society, Series A. 157: 209-230.

Brooks, R. 1991 Male and female labour force participation in New Zealand 1965-1990: A Cointegration analysis. New Zealand Economic Papers, 25, 219251.

Dreze, J. 1975 Existence of an equilibrium under price rigidity and quantity rationing. International Economic Review. 16: 301-320.

Grimes, A.1981 A model of the New Zealand labour market. Reserve Bank of New Zealand, Research Paper 33.
Harris, R.1992 Ethnicity, gender and labour supply in New Zealand in 1986. New Zealand Economic Papers, 26:199-218.

Harris, R. and L. Raney 1991 Participation and the supply of hours for New Zealand females in 1986: differences across ethnic groups. Proceedings of the New Zealand Association of Economists Conference. Auckland, August 1990.

Hyman, Prue 1979 Inter-urban variation in female labour force participation in New Zealand, 1971. New Zealand Economic Papers, 13: 115-139.

Lambert, Jean-Paul 1988 Disequilibrium macroeconomic models. Theory and estimation of rationing models using business survey data. Cambridge University Press. Cambridge.

Malinvaud, E. 1977 The theory of unemployment reconsidered. Basil Blackwell. Oxford.

Neild, P.G. 1971 Labour force participation in New Zealand. Ph.D. thesis. Victoria University of Wellington.

Rae, David 1994 NBNZ-DEMONZ. Dynamic Equilibrium Model of New Zealand. The National Bank. Working Paper 94/7.

Raney, L. 1990 Female Labour Supply in New Zealand. M.Soc.Sci. thesis. University of Waikato.

Silverstone, Brian and Susi Gorbey 1995 Labour Market Dynamics: Unemployment inflows and outflows in New Zealand 1985-1994. In Morrison, P.S. (ed) Labour, employment and work in New Zealand 1994. Victoria University of Wellington:

Sneesens, H.R. 1984 Theory and estimation of macroeconomic rationing models. Methods for quantity rationing models: A Monte Carlo comparison. European Economic Review 29:111-136.

\section{Author}

Fraser Jackson is Professor of, Economics Department of Economics at Victoria University of Wellington, PO Box 600 , Wellington. 